\title{
Identifikasi Potensi Perikanan di Kecamatan Parigi Kabupaten Pangandaran Provinsi Jawa Barat
}

\author{
[Identification of Potential Fisheries in Parigi District, Pangandaran District, \\ West Java Province]
}

\author{
Yeni Nurpajri, Ganjar Wiryati, Ade Sunaryo \\ Jurusan Penyuluhan Perikanan, Sekolah Tinggi Perikanan \\ Jalan Cikaret No. 2, Bogor Selatan, Kota Bogor 16132
}

Diterima : 8 Februari 2019; Disetujui : 14 Maret 2019

\begin{abstract}
Abstrak
Identifikasi potensi suatu wilayah merupakan salah satu kegiatan untuk menggali data dan informasi yang dilakukan secara partisipatif. Sektor kelautan dan perikanan paling banyak melibatkan masyarakat pada setiap kegiatannya sehingga menjadi salah satu sumber pertumbuhan ekonomi baru dalam rangka meningkatkan pendapatan masyarakat. Potensi perikanan tersebar diberbagai daerah termasuk Kecamatan Parigi. Kecamatan Parigi merupakan salah satu kecamatan yang berada di Kabupaten Pangandaran yang memilki desa sebanyak 10 desa. Potensi dalam bidang perikananan yang ada di Kecamatan Parigi yaitu budidaya, pengolahan dan penangkapan ikan, karena sebagian besar wilayahnya merupakan wilayah pesisir. Kecamatan Parigi memiliki jumlah RTP sebanyak 294 dan nelayan mendominasi jumlah RTP. Teknologi yang digunakan dalam semua bidang RTP yaitu tradisional, baik budidaya, pengolahan maupun penangkapan. Tujuan penelitian adalah mengumpulkan, mengolah serta menyusun data identifikasi potensi perikanan yang ada di Kecamatan Parigi. Lokasi penelitian dilaksanakan di Kecamatan Parigi pada tanggal 1-30 November 2018. Data yang dikumpulkan yaitu berupa data sekunder dan data primer, dengan menggunakan metode wawancara, kuisioner dengan observasi langsung ke lapangan. Dari 10 desa yang memiliki potensi perikanan tertinggi yaitu 5 desa yang dikembangkan dalam bidang budidaya, pengolahan serta penangkapan ikan.
\end{abstract}

Kata Kunci: Kecamatan Parigi, perikanan, potensi, RTP.

\section{Abstract}

Identification of the potential of an area is one of the activities to explore data and information carried out in a participatory manner. The marine and fisheries sector mostly involves the community in each of its activities so that it becomes one of the sources of new economic growth in the context of increasing community income. Fisheries potential is spread in various regions including Parigi District. Parigi District is one of the sub-districts in Pangandaran Regency which has 10 villages. Potentials in the fishery sector in Parigi District are aquaculture, processing and fishing, because most of the area is coastal area. Parigi District has a total number of FHs of 294 and fishermen dominate the number of FHs. The technology used in all fields of RTP is traditional, whether cultivation, processing or capture. The purpose of this research is to collect, process and compile data on the identification of potential fisheries in Parigi District. The research objective is to collect, process and compile fisheries data and analyze fisheries problems in Parigi District. The research location was carried out in Parigi District on 1-30 November 2018. The data collected in the form of secondary data and primary data, using interviews, questionnaires with direct observation to the field. Of the 10 villages that have the highest fishery potential, 5 are developed in the fields of aquaculture, processing and fishing.

Keywords: Parigi District, fisheries, potential, RTP. 


\section{PENDAHULUAN}

Wadah pembelajaran bagi pelaku utama maupun pelaku usaha perikanan tidak pernah terlepas dari media yang berkaitan dengan teknologi. Dengan adanya perkembangan teknologi, tentunya memudahkan dalam pengumpulan data dan informasi yang diperlukan dalam kegiatan penyuluhan yang akan dilakukan. Hal tersebut yang melatarbelakangi penulis memilih Kecamatan Parigi Kabupaten Pangandaran untuk dilakukan identifikasi potensi wilayah perikanan untuk mengetahui potensi sumber daya alam maupun sumber daya manusia yang ada di lokasi tersebut.

Penyuluhan perikanan agar tepat sasaran dan sesuai dengan kebutuhan sasaran, memerlukan informasi mengenai kondisi lapangan. Tujuan penyuluhan sistem agribisnis seperti perikanan harus jelas kearah terbentuknya perilaku agribisnis yang berkebudayaan industri. Metode penyuluhannya maupun media komunikasi yang digunakan dalam kegiatan penyuluhan agar lebih beragam, inovatif dan kreatif sesuai dengan kebutuhan sasaran penyuluhan. Penyuluhan sistem agribisnis juga memerlukan perubahan perilaku penyuluh, menjadi penyuluh sistem agribisnis yang professional. Penyuluh (Suparta 2003). Informasi karakteristik sasaran (SDM) dan lingkungan (SDA) perlu diidentifikasi untuk penyuluhan yang efektif (Amanah 2003)

Tujuan penelitian adalah mengumpulkan, mengolah serta menyusun data perikanan dan menganalisis identifikasi potensi perikanan di di Kecamatan Parigi.

\section{BAHAN DAN METODE}

Penelitian ini dilaksanakan pada tanggal 1-30 November 2018 di Kecamatan Parigi. Materi penelitian yang dilaksanakan dalam identifikasi potensi wilayah perikanan di Kecamatan Parigi Kabupaten Pangandaran yaitu melakukan identifikasi sumberdaya alam dan sumberdaya manusia, kegiatan produksi, kegiatan usaha dan kegiatan penyuluhan penentuan populasi dengan menggunakan Purposive sampling. Purposive yang digunakan untuk menentukan populasi yang akan diambil secara sengaja sesuai dengan pertimbangan kriteria yaitu usaha perikanan merupakan usaha pokok kelompok masih aktif.

Penentuan sampel digunakan dengan menggunakan rumus slovin 
untuk menentukan jumlah sampel responden yang akan diambil datanya. Pada pelaksanaannya, dipilih 5 desa potensial. Pemilihan desa potensial tersebut dilihat dari adanya usaha aktivitas perikanan serta pelau utama dan pelaku usaha perikanan di Kecamatan Parigi. Dalam pengambilan sampel RTP yang dapat mewakili seluruh populasi sebanyak 24 orang dan diambil dari 3 bidang usaha yaitu penangkapan, pengolahan serta budidaya. Pengumpulan data dilakukan dengan studi literature dan wawancara langsung dengan pelaku usaha. Analisis masalah dilakukan dengan menggunakan Problem Tree Analysis.

\section{HASIL DAN PEMBAHASAN}

\section{Sumber Daya Alam}

Kecamatan Parigi memiliki luas wilayah $\pm 100,149 \mathrm{~km}^{2}$. yang terdiri dari lahan sawah seluas 2.095 ha, tanah kering 8.687.57. sedangkan keadaan tofografi termasuk kedalam klasifikasi daerah dataran rendah dan pesisir sampai dengan dengan ketinggian 5 160 meter diatas permukaan laut. Jenis tanah wilayah Kecamatan Parigi sebagian besar termasuk jenis latosol dan sebagian kecil jenis grumosol, dengan $\mathrm{pH} 5$ sampai 5,5 . Suhu udara bervariasi. Kondisi geografis desa, dan iklim secara rinci dapat dilihat pada Tabel 1.

Salah satu Kecamatan yang telah ditetapkan sebagai Kawasan Usaha Perikanan dan Ibu kota Kabupaten Pangandaran yaitu Kecamatan Parigi. Hal ini dikarenakan, Kecamatan Parigi memiliki potensi sumber air yang berlimpah yang diperoleh setiap saat karena merupakan alur perlintasan saluran air dari mata air dengan ketersediaan air sepanjang tahun

Tabel 1. Statistik Geografi dan Iklim Parigi Tahun 2018

\begin{tabular}{ccc}
\hline \multicolumn{3}{c}{ Lokasi Geografis Desa } \\
\hline Pesisir & Desa & 2 \\
Lembah & Desa & - \\
Lereng & Desa & 2 \\
Dataran & Desa & 6 \\
\hline \multicolumn{2}{l}{ Rklim } \\
$\begin{array}{llc}\text { Huja-rata Curah } \\
\text { Jumlah hari Hujan }\end{array}$ & $\mathrm{mm}^{3}$ & 353,88 \\
\hline
\end{tabular}

Sumber: BPS (2018a) 


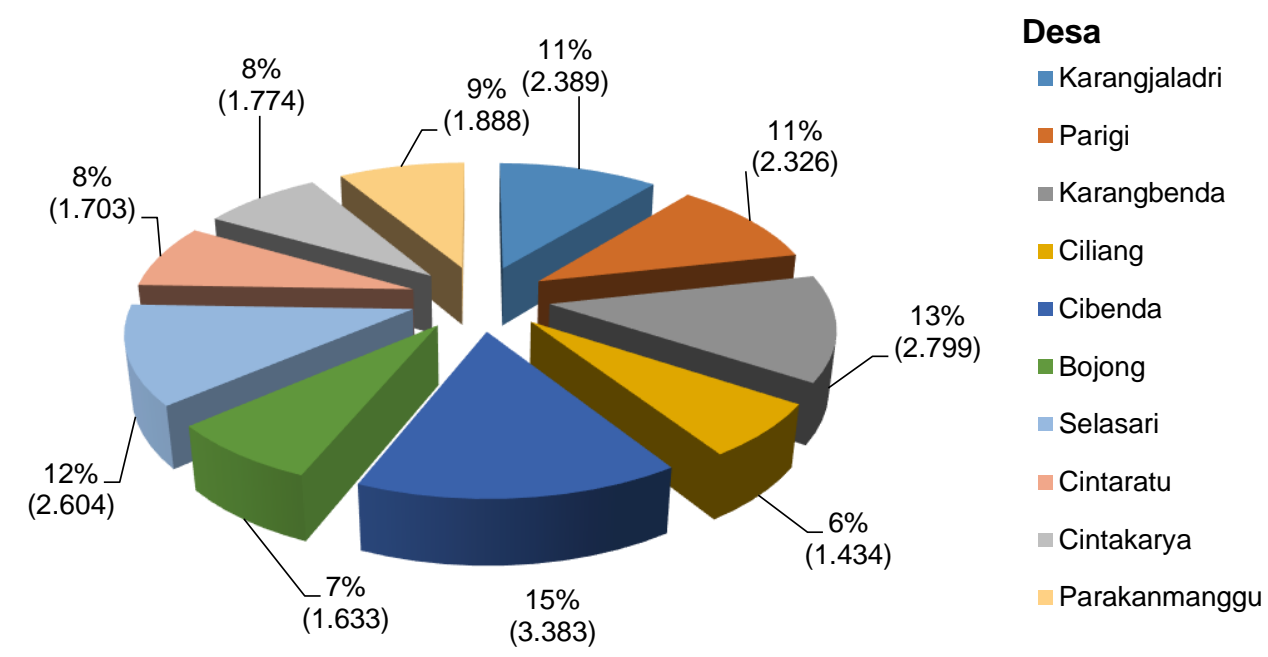

Gambar 1 Grafik Jumlah penduduk per desa di Kecamatan Parigi Sumber: BPS (2018b)

sehingga sangat memungkinkan dilakukannya kegiatan usaha perikanan di kawasan kecamatan tersebut dan pantai pesisir memiliki potensi bagus untuk usaha perikanan dari pengolahan atau penangkapan. (BPS 2018b)

Karakteristik demografi desa-desa di Kecamatan Parigi memiliki kontour berbukit dan terletak di pesisir pantai. Kecamatan tersebut merupakan salah satu kecamatan yang ditetapkan sebagai kawasan usaha perikanan di Kabupaten Parigi. Hal ini dikarenakan, Kecamatan Parigi memiliki potensi perikanan yang melimpah baik itu di perikanan tangkap, budidaya, maupun pengolahan hasil perikanan.

\section{Sumber Daya Manusia}

Jumlah Penduduk Kecamatan

Parigi sebanyak 44.529 Jiwa terdiri dari :

Laki-laki : 21.933 jiwa $\begin{array}{ll}\text { Perempuan } & : 22.596 \text { jiwa } \\ \text { Jumlah KK } & : 16.206 \text { KK }\end{array}$

Jumlah penduduk yang berada di Kecamatan Parigi dapat dikelompokkan berdasarkan jenis kelamin, data dilihat pada Grafik 1.

Jumlah Penduduk selain dilihat dari jenis kelamin juga dapat dilihat menurut tingkat pendidikan. Berikut penduduk menurut pendidikan dapat dilihat pada Grafik 2.

Berdasarkan Grafik tingkat pendidikan di Kecamatan Parigi masih sangat kurang terbukti dengan banyaknya masyarakat yang tidak menyelesaikan pendidikan dan banyak lulusan SD. Kurangnya tingkat pendidikan dikarenakan kurangnya kesadaran masyarakat akan pentingnya 


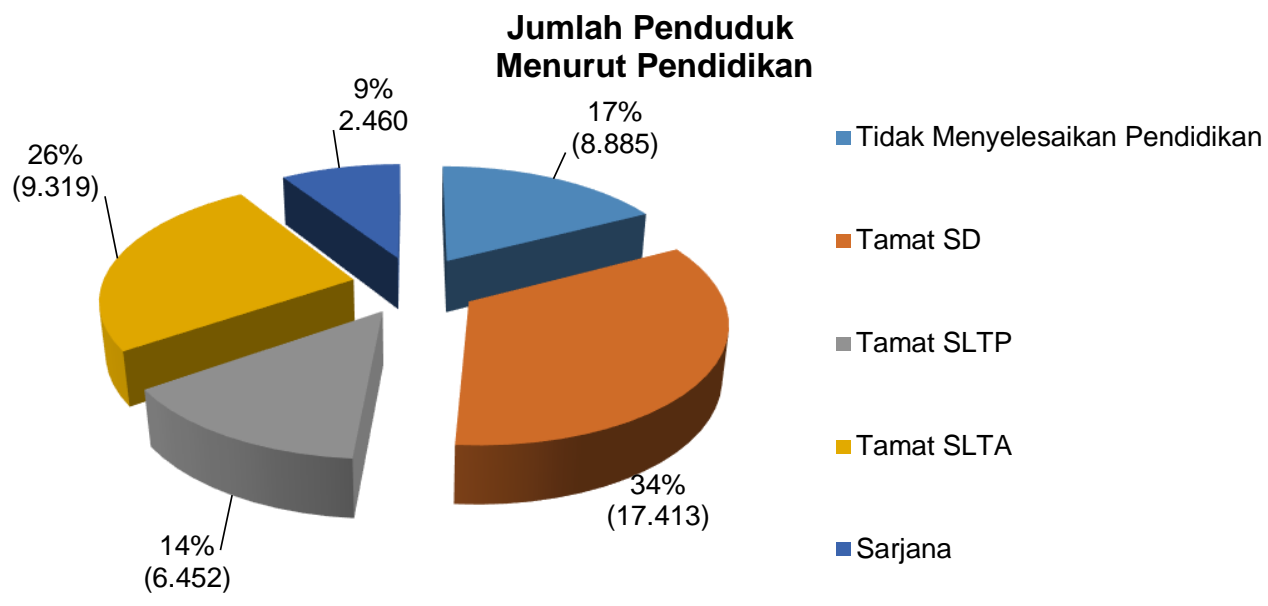

Gambar 2 Grafik Jumlah penduduk Menurut Pendidikan

Sumber: Data Sekunder Kecamatan Parigi 2018

untuk mengenyam ilmu pengetahuan serta faktor ekomoni yang tidak mendukung. Hal ini akan berpengaruh pada tingkat penerimaan informasi (Anjani 2018) dan teknologi perikanan baru (Warsito 2018).

\section{Kondisi Umum Usaha Perikanan}

Kecamatan Parigi memiliki jenis usaha yang berdasar pada potensi perikanan yang ada, kegiatan usaha tersebut yaitu penangkapan ikan, budidaya, dan pengolahan. Potensi areal budidaya air tawar di Kecamatan Parigi masih menggunakan teknologi tradisional dengan jenis ikan yang dibudidayakan yaitu ikan lele dan ikan nila serta sumber air yang digunakan berasal dari mata air penggunungan di Desa Parakan Manggu akan tetapi pemanfaatannya lebih banyak digunakan untuk kegiatan pertanian. Sumber air pegunungan dapat dimanfaatkan untuk budidaya ikan lele (Andriyanto dan Septyan 2013). Kegiatan penangkapan ikan di desa Karangjaladri menggunakan kapal fibreglass 2 GT dan alat tangkap yang digunakan yaitu jaring dengan ratarata menangkap ikan layur, tiga waja, udang jerebung . Kapal berbahan fibre glass lebih tahan lama dan kuat jika dibandingkan dengan kapal kayu yang mudah lapuk, serta perawatan kapal fiber lebih mudah daripada kapal kayu (Yulianto et al. 2013). Kegiatan penanganan dan pengolahan ikan yang baik bertujuan untuk mempertahankan mutu dan kesegaran ikan selama mungkin dengan cara menghambat penyebab kemunduran mutu (pembusukan) maupun penyebab kerusakan ikan, agar ikan tetap baik sampai ke tangan konsumen (Nurani, Murdaniel, dan Harahap 2013). Proses pengolahan ikan dapat meningkatkan diversifikasi produk perikanan dan 
pembuatan kemasan yang menarik sehingga nilai jualnya semakin meningkat (Agustini dan Swastawati 2003), sekaligus dapat meningkatkan pendapatan pembudidaya ikan atau nelayan, sehingga mereka terdorong untuk meningkatkan produksi perikanan jenis olahan yang dilakukan yaitu ikan asin yang dilakukan oleh 14 orang dan tergabung menjadi sebuah kelompok pengolahan ikan.

\section{Sistem Produksi Perikanan}

Produksi pengolahan hasil perikanan berupa ikan asin dengan menggunakan perlatan sederhana yaitu peralatan tumah tangga dari tahap menyiangan sampai penjemuran. Bahan baku yang digunakan diperoleh dari nelayan langsung dari Parigi. Terkadang bahan baku diambil juga dari luar daerah Parigi yaitu dari Pacitan apabila kekurangan pasokan bahan baku, Bahan baku kemudian langsung diolah menjadi olahan ikan asin.Proses pembuatan ikan asin berlangsung selama sampai 3 hari untuk mendapatkan hasil maksimal karena proses pengeringan tergantung cuaca. Pengeringan menggunakan panas matahari selain biaya murah, juga mempunyai daya tampung yang besar. Akan tetapi cara ini sangat tergantung pada cuaca dan suhu pengeringan tidak dapat diatur. Alternatif pengeringan adalah dengan menggunakan oven.
Keuntungan pengeringan oven yaitu suhu dan waktu pemanasan dapat diatur. Oven dapat dimodifikasi sehingga ikan asin dapat diproduksi dengan kapasitas yang lebih banyak (Riansyah, Supriadi, dan Nopianti 2013).

$$
\text { Tahapan proses produksi }
$$
penangkapan ikan berupa penyediaan es, penyediaan BBM serta penyediaan logistik. Nelayan menggunakan jaring sebanyak 20 set dan proses penebaran jaring bisa sampai 1 jam. Nelayan memperoleh ikan daerah penangkapan nelayan yaitu di lautan daerah Batukaras, Teluk Parigi, Cijulang. Hal ini sesuai dengan Undang-Undang Republik Indonesia No.45 Tahun 2009 Tentang Perikanan, penangkapan ikan adalah kegiatan untuk memperoleh ikan di perairan yang tidak dalam keadaan dibudidayakan dengan alat atau cara apapun, termasuk kegiatan yang menggunakan kapal untuk memuat, mengangkut, menyimpan, mendinginkan, menangani, mengolah, dan/atau mengawetkannya. Penangkapan ikan biasanya dilakukan oleh seorang nelayan. Produksi pembesaran dan pembenihan ikan berupa penyediaan pasokan input seperti sarana prasarana, benih ikan, induk obat-obatan, dll masih dapat dipasok dari pasar lokal yaitu sekitar wilayah Kabupaten Pangandaran. 
Sistem Bisnis Perikanan

Kegiatan usaha rata-rata masyarakat menggunakan modal pribadi kemudian dipergunakan untuk kebutuhan produksi berupa alat dan barang yang diperlukan dalam kegiatan proses produksi. Hal ini sesuai dengan pernyataan (Rahardi, Regina, dan Nazaruddin 2008) yang menyatakan bahwa modal adalah barang- barang bernilai ekonomis untuk kelayakan/ meningkatkan produksi. Produksi untuk bahan baku pengolahan ikan asin maka perlu dilakukan penyiapan bahan baku ikan manyung terlebih dahulu. Kegiatan pengolahan ikan asin bertujuan untuk mempertahankan ikan dari proses pembusukan. Hal ini sesuai dengan pernyataan Adawyah (2007) bahwa pengolahan hasil perikanan merupakan salah satu cara untuk mempertahankan ikan dari proses pembusukan, sehingga mampu disimpan lama sampai tiba waktunya untuk dijadikan sebagai bahan konsumsi. Responden nelayan menjelaskan bahwa dalam melakukan produksi usaha penangkapan ikan dilakukan penyiapan alat tangkap, menyiapkan kapal serta menyiapkan bahan bakar. Kemudian untuk budidaya ikan dalam melakukan proses produksi budidaya perlu menyiapkan wadah dan persiapan induk untuk pembenihan dan untuk pembesaran persiapan kolam dan benih yang akan digunakan. Pada proses kegiatan panen dimulai dari pukul 07.00 WIB hingga pukul 09.00 WIB, guna menghindari ikan terkena sinar paparan matahari langsung dan fluktuasi suhu yang hebat. Hal ini sesuai dengan pernyataan (Khairuman dan Amri 2003) bahwa suhu yang baik saat melakukan panen dan pengangkutan berkisar 15$20^{\circ} \mathrm{C}$. Suhu ini sesuai karena suhu pagi hari di kawasan Kecamatan Parigi berkisar $16-20^{\circ} \mathrm{C}$.

Pemasaran yang dilakukan adalah untuk meningkatkan pendapatan. Ha ini sesuai dengan pernyataan Firdaus (2009) bahwa pemasaran merupakan salah satu kegiatan pokok yang harus dilakukan seorang pengusaha untuk mendapatkan laba dan berkembang. Dalam memasarkan hasil produksinya untuk budidaya akan dipasarkan ke pengepul yang ada di Kecamatan Parigi dengan melakukan perjanjian terlebih dahulu sebelum ikan dipanen, kemudian pengepul datang langsung ke tempat pembudidaya. Untuk pengolahan produsen memasarkan produknya langsung kepada konsumen dan dapat langsung ke tempat produksi. Serta untuk kegiatan penangkapan ikan, nelayan membawa hasil tangkapannya secara langsung dijual ke TPI.

Sumber daya penunjang terdapat di Kecamatan Parigi untuk menunjang usahanya yaitu koperasi, pasar, industri rumah tangga, Bank dan TPI. Hal ini 
sesuai dengan pernyataan (Laksana 2008) Keberhasilan suatu usaha bisnis perikanan dalam modernisasi tidak dapat lepas dari peran dan jasa lembaga lembaga terkait. Lembaga - lembaga tersebut adalah Pemerintah, Lembaga Pembiayaan, Lembaga Pemasaran dan Industri, Pengangkutan (Transportasi), Komunikasi.

\section{Analisis Usaha}

Analisis suatu usaha / investasi perlu dilakukan untuk mengetahui kelayakan dan perkembangan usaha. Beberapa metode analisis yang dapat dipergunakan antara lain Revenue Cost Ratio (R/C Ratio), Break Event Point (BEP) atau titik impas dan Payback Period (Praptokardiyo dan Muskitta 2012). Analisis usaha juga berkaitan dengan kelayakan suatu usaha untuk dijalankan atau tidak, sehingga membantu pelaku utama dalam mengambil keputusan untuk meneruskan atau memberhentikan usaha yang dijalankan. Rata-rata analisis usaha pada Bidang Penangkapan, Pengolahan dan Budidaya dapat dilihat pada Tabel 2.

\section{Sistem Penyuluhan Perikanan}

Sasaran penyuluhan yaitu pelaku utama dan pelaku usaha perikanan yang berada di Kecamatan Parigi. Sebaran penyuluh perikanan di lingkup Kabupaten Pangandaran yang tercatat hingga bulan November 2018 meliputi penyuluh PNS sebanyak enam orang, penyuluh perikanan bantu (PPB) sebanyak delapan orang dengan wilayah kerja yang berbeda-beda. Penyuluh perikanan di Kecamatan Parigi terdapat

Tabel 2. Rata-rata Analisa Usaha Penangkapan

\begin{tabular}{llr}
\hline No & \multicolumn{1}{c}{ Keterangan } & \multicolumn{1}{c}{ Nominal } \\
\hline 1 & Biaya Investasi & Rp. 54.439 .699 \\
2 & Biaya Tetap & Rp. 2.363 .441 \\
3 & Biaya Variabel & Rp. 6.668 .080 \\
4 & Biaya Produksi & Rp. 9.031 .522 \\
5 & Pendapatan & Rp. 15.585 .571 \\
6 & Keuntungan & Rp. 6.554 .049 \\
7 & R/C Ratio & 1,7 \\
8 & BEP (Unit) & $123 \mathrm{Kg}$ \\
9 & BEP (Rp) & Rp. 4.094 .943 \\
10 & ROI & $73 \%$ \\
11 & PP & 9,4 \\
\hline
\end{tabular}

Sumber: Data Primer, 2018 
Tabel 3. Rata-rata Analisa Usaha Pengolahan

\begin{tabular}{llr}
\hline No & \multicolumn{1}{c}{ Keterangan } & \multicolumn{1}{c}{ Nominal } \\
\hline 1 & Biaya Investasi & Rp. Rp. 6.905 .000 \\
2 & Biaya Tetap & Rp. 115.275 \\
3 & Biaya Variabel & Rp. 1.765 .000 \\
4 & Biaya Produksi & Rp5.410.275 \\
5 & Pendapatan & Rp. 9.600 .000 \\
6 & Keuntungan & Rp. 4.189 .725 \\
7 & R/C Ratio & 1,7 \\
8 & BEP (Unit) & 3 Bungkus \\
9 & BEP (Rp) & Rp. 261,988 \\
10 & ROI & $77 \%$ \\
11 & PP & 0,13 \\
\hline
\end{tabular}

Sumber: Data Primer, 2018

dua orang yaitu penyuluh PNS dan PPB. media penyuluhan yang biasa digunakan dalam kegiatan penyuluhan antara lain; media tertayang, leaflet, folder, brosur, poster. Sarana dan prasarana penyuluhan berupa kendaraan, komputer, projector, aula atau tempat, media penyuluhan. Dalam UndangUndang No. 16 tahun 2006 tentang Sistem Penyuluhan Pertanian, Perikanan dan Kehutanan (SP3K) Pasal 31 ayat 1, yaitu untuk meningkatkan kapasitas kelembagaan penyuluhan dan kinerja penyuluh, diperlukan sarana dan prasarana yang memadai agar penyuluhan dapat diselenggarakan dengan efektif dan efisien. Sumber pembiayaan untuk penyuluhan disediakan melalui APBN baik provinsi maupun kabupaten/kota, baik secara sektoral maupun lintas sektoral, maupun sumber-sumber lain.

\section{Analisis Masalah}

Analisis masalah dilakukan dengan menetapkan permasalahan adalah Tree Analysis. Setelah dianalisis, maka ditemukan akar permasalahan mengenai permasalahan teknis, ekonomi dan sosial. Permasalahan dari aspek teknis antara lain: kurangnya pks mengenai Kurangnya pengetahuan mengenai pengemasan produk yang menarik; kurangnya PKS dalam Kurangnya penanganan hasil tangkapan, Kurangnya pengetahuan pembuatan pakan alternatif. Permasalahan dalam aspek usaha antara lain modal belum maksimal hal tersebut disebabkan karena kurangnya pengetahuan mengenai 
Tabel 4. Rata-rata Analisa Usaha Pembenihan

\begin{tabular}{llr}
\hline No & \multicolumn{1}{c}{ Keterangan } & Nominal/Angka \\
\hline 1 & Biaya Investasi & Rp. 9.000 .000 \\
2 & Biaya Tetap & Rp. 8.000 .000 \\
3 & Biaya Variabel & Rp. 1.275 .000 \\
4 & Harga Jual & Rp. 5.890 .000 \\
5 & Produksi & Rp. 58.900 \\
6 & Biaya Produksi & Rp. 9.275 .000 \\
7 & Pendapatan & Rp. 5.890 .000 \\
8 & Keuntungan & Rp. 4.615 .000 \\
9 & R/C Ratio & 4,6 \\
10 & BEP( unit) & $102,040 \mathrm{~kg}$ \\
11 & BEP (Rp) & Rp. 13.333 .333 \\
12 & ROI & $51,2 \%$ \\
13 & PP & 1,9 \\
\hline
\end{tabular}

Tabel 5. Rata-rata Analisa Usaha pembesaran ikan Lele

\begin{tabular}{llr}
\hline No & \multicolumn{1}{c}{ Keterangan } & \multicolumn{1}{c}{ Nominal } \\
\hline 1 & Biaya Investasi & Rp. 1.389 .981 \\
2 & Biaya Tetap & Rp. 392.700 \\
3 & Biaya Variabel & Rp. 2.634 .950 \\
4 & Harga Jual & Rp. 18.000 \\
5 & Biaya Produksi & Rp. 3.027 .651 \\
6 & Pendapatan & Rp. 4.114 .800 \\
7 & Keuntungan & Rp. 1.087 .149 \\
8 & R/C Ratio & 1,3 \\
9 & BEP( ekor) & $59 \mathrm{~kg}$ \\
11 & BEP (Rp) & Rp. 1.056 .727 \\
12 & ROI & $36 \%$ \\
13 & PP & 1,3 \\
\hline
\end{tabular}

peminjaman modal; pendapatan belum maksimal dikarenakan kurangnya PKS mengenai pengembangan kemasan produk. Permasalahan dalam aspek sosial yaitu kegiatan kelompok yang belum berjalan maksimal dikarenakan kurangnya pemahaman pelaku usaha dan pelaku utama mengenai pentingnya berkelompok. 


\section{SIMPULAN DAN SARAN}

\section{Simpulan}

1. Kecamatan Parigi memiliki luas wilayah $10782.57 \mathrm{Ha}$, memiliki ketersediaan air sepanjang tahun sehingga cocok digunakan sebagai lahan pengelolaan usaha perikanan dengan Jumlah Penduduk sebanyak 44.529 Jiwa. Terdapat 294 RTP dan memiliki 5 desa potensial tertinggi dalam perikanan yaitu desa Karangjaladri, desa Karangbenda, desa Bojong, desa Cibenda dan desa Parakanmanggu.

2. Kegiatan usaha budidaya di Kecamatan Parigi dimulai dari persiapan wadah budidaya sampai dengan proses pemanenan. Dalam proses produksinya usahanya menggunakan teknologi tradisional.

3. Kegiatan usaha penangkapan di Kecamatan Parigi Kabupaten Pangandaran dimulai dari persiapan alat tangkap, persiapan kapal, penyediaan sarana produksi, logistik, dan hauling atau penanganan setelah penangkapan.

4. Kegiatan usaha pengolahan ikan asin di Kecamatan Parigi Kabupaten Pangandaran masih berjalan dan menjadi ciri khas ikan asin Pangandaran.

5. Kegiatan usaha pengolahan asin di Kecamatan Parigi Kabupaten Pangandaran dimulai dengan menyiapkan bahan baku, peyiangan, pencucian, penggaraman, pengeringan dan pengemasan.

6. Sistem penyuluhan di Kecamatan Parigi belum dilakukan secara optimal karena penyuluh yang terbatas dan kurangnya intensitas kunjungan terhadap pelaku usaha terutama penangkapan.

\section{Saran}

Jumlah bahan baku yang terkadang kurang untuk kegiatan pengolahan ikan asin, dapat diatasi yaitu perlu peningkatan persiapan bahan baku namun untuk meningkatkan pemasaran perlu perbaikan produk. Peran dan pendampingan penyuluh terhadap pelaku utama perlu ditingkatkan agar pelaku utama dapat mengadopsi teknologi yang lebih maju, sehingga meningkatkan produksi mapun produktifitas usahanya. Pemasaran produk perlu adanya fasilitator yang menghubungkan antara pelaku utama dan lembaga pemasaran

\section{DAFTAR PUSTAKA}

Adawyah, Rabiatul. 2007. Pengolahan dan pengawetan ikan. Bumi Aksara. Agustini, Tri Winarni dan Fronthea Swastawati. 2003. "Pemanfaatan Hasil Perikanan Sebagai Produk Bernilai Tambah (Value-Added) 
dalam Upaya Penganekaragaman

Pangan." Jurnal. Teknol. dan Industri Pangan, XIV(1):74-81.

Amanah, Siti. 2003. "Perencanaan

Program Penyuluhan Perikanan di

Desa Anturan, Buleleng, Bali."

Buletin Ekonomi Perikanan 5(1):120.

Andriyanto, Willy Nofian dan Muhammad

Septyan. 2013. "Manajemen

Budidaya Ikan Lele Dumbo (Clarias gariepinus) di Kampung Lele,

Kabupaten Boyolali, Jawa Tengah." Media Akuakultur 8(1):63-72.

Anjani, Putu Widya. 2018. "Pengaruh Usia , Pengalaman Kerja , Tingkat Pendidikan, dan Kompleksitas Tugas terhadap Efektivitas Pengguna Sistem Informasi Akuntansi Fakultas Ekonomi dan Bisnis Universitas Udayana ( Unud ), Bali , Indonesia Fakultas Ekonomi dan Bisnis Universitas Uday." EJurnal Akuntansi Universitas Udayana 22(3):2430-57.

BPS. 2018a. Kabupaten Pangandaran Dalam Angka 2018. Pangandaran (ID): Badan Pusat Statistik Pangandaran.

BPS. 2018b. Kecamatan Parigi Dalam Angka 2018. Pangandaran (ID): Badan Pusat Statistik Pangandaran.

Firdaus, Muhammad. 2009. Manajemen Agribisnis. Bumi Aksara.
Khairuman dan Khairul Amri. 2003. Budidaya Ikan Nila Secara Intensif. Depok (ID): Agromedia Pustaka.

Laksana, Fajar. 2008. Agribisnis Perikanan. Jakarta (ID): Penebar Swadaya.

Nurani, Tri W., Rama P. S. Murdaniel, dan Muklis H. Harahap. 2013. “Upaya Penanganan Mutu Ikan Tuna Segar Hasil Tangkapan Kapal Tuna Longline untuk Tujuan Ekspor." Marine Fisheries 4(2):15362.

Praptokardiyo, Kardiyo dan Willem

Muskitta. 2012. Manajemen

Produksi Operasi Budidaya

Perairan. Bogor (ID).

Rahardi, F., K. Regina, dan Nazaruddin. 2008. Agribisnis Perikanan. Jakarta (ID): Penebar Swadaya.

Riansyah, Angga, Agus Supriadi, dan Rodiana Nopianti. 2013. "Pengaruh Perbedaan Suhu dan Waktu Pengeringan Terhadap Karakteristik Ikan Asin Sepat Siam (Trichogaster pectoralis) dengan Menggunakan Oven." Jurnal FishtecH 2(1):53-68.

Suparta, Nyoman. 2003. "Penyuluhan sistem agribisnis suatu pendekatan holistik." SOCA (Socio-Economic Of Agriculturre And Agribusiness) $3(2): 1-16$.

Warsito. 2018. "Adopsi Teknologi Budidaya Ikan Nila di Desa Padang 
Jaya Kecamatan Padang Jaya

Kabupaten Bengkulu Utara."

Bengkulu.

Yulianto, Eko Sulkhani, Budhi Hascaryo Iskandar, Fis Purwangka, dan Wazir Mawardi. 2013. "Desain Perahu Fiberglass Bantuan LPPM IPB di

Desa Cikahuripan, Kecamatan Cisolok , Sukabumi." Buletin PSP 21(1):31-50. 
